\title{
Improving the Time Performance of Prefabricated Construction Projects: A Review
}

\author{
Yilu $\mathrm{Xu}^{1}$ \\ ${ }^{1}$ Nanjing Forestry University China
}

\begin{abstract}
Prefabricated construction, as innovative construction technology, has been gradually applied in the construction industry in recent decades. However, little research has focused on the factors which affect the project schedule of prefabricated construction. Therefore, this review aims to systematically identify and classify determinants that influence the schedule of prefabricated constructions. Based on the literature review, 13 factors that influence the schedule performance of prefabricated construction projects are identified and classified into 7 categories: design, construction techniques, collaboration, coordination, and communication between participants, supply chain, owner, human resource, external conditions. The findings of this study provide valuable clues for both researchers and project practitioners to efficiently implement prefabricated construction projects. Future research directions are also provided.
\end{abstract}

\section{Introduction}

Prefabricated construction, as innovative construction technology, has been gradually applied in the construction industry in recent decades. Prefabricated construction is defined as the processes of designing and manufacturing building modules in prefabrication factories, and then transporting and installing these modules to a greater degree of finish on construction sites [1,2], which can shorten construction time and increase construction productivity, ameliorate working environment, enhance construction quality, improve sustainability performance (Construction Industry Council, 2018). Due to these advantages, it has been increasingly used in multiple types of projects such as residential buildings and industrial plants [4]. Moreover, because of its fast speed in construction, prefabricated construction has emerged as a critical construction method for building emergency hospitals. For example, amid the COVID-19 pandemic, China used this method to build two emergency hospitals (i.e., Huoshenshan hospital and Leishenshan hospital) within ten days, which have saved thousands of lives of the patients infected by the coronavirus [3]. The important role of prefabricated construction methods in this example indicates that it has a wide prospect of application in speedy construction.

Existing research has investigated various critical success factors or barriers for prefabricated construction projects[4]. However, little research has focused on the factors which affect the project schedule of prefabricated construction. The schedule performance of prefabricated construction projects depends on complex factors during its delivery since the involvement of owners, designers, suppliers, engineers, and contractors [4]. Therefore, this review aims to systematically identify and classify determinants that influence the schedule of prefabricated constructions.

\section{Factors affecting project progress in prefabricated projects}

Based on the research objectives, keywords such as "prefabricated constructions", "offsite building", "industrialized building", "schedule", and "delay" were used for searching the literature and around 30 relevant papers were found. The author then conducted thematic content analysis and identified 13 factors that influence the schedule performance of prefabricated construction projects. Table 1 summarizes these factors from the included studies, which are further classified into 7 categories according to different areas of impact. aims to systematically identify and classify determinants that influence the schedule of prefabricated constructions.

Table1. key Factors affecting the schedule performance of prefabricated constructions.

\begin{tabular}{|c|c|c|}
\hline Category & Factors & Reference \\
\hline 1.Design & $\begin{array}{l}\text { Early design freeze } \\
\text { and timely approval } \\
\text { from owners }\end{array}$ & {$[5] ;[4] ;[6]$} \\
\hline $\begin{array}{l}\text { 2.Construction } \\
\text { techniques }\end{array}$ & Standardization & [9];[4]; [8] \\
\hline \multirow{2}{*}{$\begin{array}{l}\text { 3.Collaboration, } \\
\text { coordination, } \\
\text { and } \\
\text { communication } \\
\text { between } \\
\text { participants }\end{array}$} & $\begin{array}{l}\text { Sufficient } \\
\text { communication and } \\
\text { effective } \\
\text { collaboration }\end{array}$ & {$[8 ;[12]$} \\
\hline & $\begin{array}{l}\text { Early participation } \\
\text { of key stakeholders } \\
\text { and fully-integrated } \\
\text { project delivery } \\
\text { methods }\end{array}$ & {$[11] ;[10]$} \\
\hline
\end{tabular}




\begin{tabular}{|c|c|c|}
\hline 4.Supply chain & $\begin{array}{l}\text { Supply chain } \\
\text { integration }\end{array}$ & {$[13] ;[14]$} \\
\hline & $\begin{array}{l}\text { Manufacturer's } \\
\text { experience, } \\
\text { competence, and } \\
\text { equipment in } \\
\text { modules design and } \\
\text { production }\end{array}$ & [15] \\
\hline \multirow[t]{2}{*}{ 5.Owner } & $\begin{array}{l}\text { Appropriate } \\
\text { procurement } \\
\text { strategy }\end{array}$ & {$[12] ;[16] ;[17]$} \\
\hline & $\begin{array}{l}\text { Effective } \\
\text { management of } \\
\text { contractor }\end{array}$ & [8] \\
\hline \multirow[t]{2}{*}{$\begin{array}{l}\text { 6.Human } \\
\text { resource }\end{array}$} & $\begin{array}{l}\text { Availability of } \\
\text { experienced } \\
\text { workforce }\end{array}$ & [8] \\
\hline & $\begin{array}{l}\text { Competent } \\
\text { contractors and } \\
\text { manufacturers }\end{array}$ & [4] \\
\hline \multirow[t]{3}{*}{$\begin{array}{l}\text { 7.External } \\
\text { conditions }\end{array}$} & $\begin{array}{l}\text { Transportation } \\
\text { conditions }\end{array}$ & {$[18 ;[8]$} \\
\hline & Regulations & {$[18] ;[20]$} \\
\hline & Weather & [21]; [13];[18] \\
\hline
\end{tabular}

\subsection{Design-Early design freeze and timely approval form owners}

Given the fast-speed of project delivery, accurate design, and early design freeze is indispensable for the prefabricated construction projects to proceed to the manufacturing stage [5]. Early design freeze forms proper time of delivery, provides the chance to mocks-up testing and pre-site prototyping [5]. Besides, early design freeze can mitigate unpredictable risks generated from the changes of design by integrating the design process, decreasing changes, and requiring each part of the design to complete promptly [4]. Reducing interdependency between different modules and enabling changes in designer orders are suggested as vital approaches to decrease the possibility of changes [6]. To secure sufficient time for the operation of the modules fabricator, designers should strive to get the timely approval from the owner to enable the early design freeze [7].

\subsection{Construction Standardizations}

\section{techniques}

and

During the project, technical factors including poorquality installation technology and inappropriate lifting equipment could negatively influence the time performance of prefabricated construction projects [8].

Since the modules are often bespoke for a specific prefabricated project, which requires the precise production of each module in terms of volume and may result in a longer time [9]. Standardization of the modules can improve the productivity of the manufacturing of the building elements, which allows project schedules to meet the requirements of the prefabricated project [4]. Standardization in prefabricated construction projects also could reduce the cost since economies of scale. Nevertheless, there is also some criticism on the prefabricated construction projects because of the separate manufacturing of different components of prefabricated construction buildings, which results in inadequate coordination. Besides, high accuracy installation technology is important for the prefabricated construction project, particularly for the progress connection[8], which affects the fluency of the schedule.

\subsection{Collaboration, coordination, and communication between participants \\ 2.3.1 Early participation of key stakeholders and fully-integrated project delivery methods}

The involved participants of the prefabricated constructions include owners, designers, and contractors, all of which are essential to the prefabricated construction project delivery according to extensive articles [4]. These important project participants involved in the whole process of a prefabricated construction project. Coordination and collaboration among various project participants in selecting optimal construction technologies and materials are critical to speed up the process of prefabricated construction projects [10]. Therefore, the fully-integrated methods enable early participation and provide opportunities for all the participants to share information and knowledge through concerted effort, which helps to develop a coadjutant and mutually supportive atmosphere in the course of the prefabricated construction project.

\subsubsection{Sufficient communication and effective collaboration}

The efficient communication and collaboration of various stakeholders are required for the efficient and successful execution of prefabricated construction projects [11]. The solid working relationship, communication, and resources exchange is crucial to enhance the efficiency of the prefabricated construction projects. [12] Rentschler et al. (2016) conclude that the collaboration of the designers, suppliers, and owners at the beginning of the projects is indispensable because their collective communication could help the supplier lead to some best design ideas. Without sufficient communication, the suppliers would likely manufacture inappropriate even problematic modules based on the technical standards that were unfamiliar to them, which could thereby cause delays to the projects.

Effective and efficient collaborations among project stakeholders are also critical for improving time performance. For example, the processes of general building construction are usually calculated by day. However, in the construction of Huoshenshan hospital in Wuhan, China, all design and construction activities were counted by hours or even minutes. All the designers, construction engineers, workers, and supervisory personnel are required to be on-site and work concurrently, which saved considerable time. 


\subsection{Supply chain}

\subsubsection{Supply chain integration}

The supply chain of the prefabricated construction project consists of processes such as engineering, fabricating, transportation, installation, which are fragmented but interdependent [13]. These features could create uncertainties during the implementation and result in extra time and effort to deal with. Therefore, before and during the project implementation, it is necessary to take effective measures to integrate and extend the coordination of all the links of the supply chain to ensure smooth delivery and improve time performance of the prefabricated construction projects[14].

For instance, in the construction of Huoshenshan hospital, with the support of the entire supply chain of the leading contractor's (i.e., China Construction Group), a large amount of the needed resources such as more than 2500 large-scale equipment and transport vehicles, more than 4900 containers, and 200000 square meters of impervious membrane arrived in Wuhan in just a few days, providing a guarantee for the overall acceleration of the hospital construction[19].

\subsubsection{Manufacturer's experience, competence, and equipment in modules design and production}

Sometimes, limited by the manufacturing capability, the manufacturer will spend more time on cross-border procurement, which may result in longer project duration and costly transportation expenses [15]. Hence, to avoid project delay caused in the procurement process, the owners and contractors need to select the competent and experienced manufacturers to design and produce the modules [15].

\subsection{Owner}

\subsubsection{Appropriate procurement strategy}

To shorten delivery time, a prefabricated project must take procurement tactics and contracting strategy into consideration[12], which was mentioned in many publications. Improved procurement strategy plays an important part in speeding up prefabricated construction projects. For example, [16]Tam elaborate on the advantage and necessity of design-build delivery methods. Prepared with bid-build procurement delivery methods, design-build delivery methods has bilateral benefit in design and construction and could create a collaborative atmosphere and make the owner and the team members work together, which promote the progress of the prefabricated construction projects[4]. No matter which strategy the owner uses, it is claimed that procurement in prefabricated construction projects could be optimized by improving collaboration between project parties and effectively integrating producers and suppliers in decision-making [17].

\subsubsection{Effective management of contractors}

Time assessment aims to decompose and manage projects properly. Therefore during the process of prefabricated construction projects, avoiding ineffective time planning and scheduling is important to decrease the possibility of a delay. Besides, stronger supervision in site management could improve the efficiency of prefabricated construction projects. [8]

\subsection{Human resource}

\subsubsection{Availability of experienced workforce}

Theoretically, prefabricated construction processes require less labor force than the traditional on-site construction. However, in practice, there is still high demand in the workforce for both manufacturing processes and on-site activities in prefabricated construction projects, particularly for the workforce with experience and advanced machine-oriented skills [8]. In China, because of the expensive training related to prefabricated construction, many construction workers lack of systematic knowledge and essential skills such as assembly techniques. This results in insufficient proficiency and low productivity in the construction process, which would harm schedule performance as well as quality issues [8].

\subsubsection{Competent manufacturers and contractors}

The progress of prefabricated construction projects depends on the ability of the manufacturer. When selecting the manufacturers, factors such as the past performance in prefabricated construction projects, manufacturing ability, and experience in different types of projects need to be taken into consideration[4]. The competence of contractors plays a critical role in accelerating the construction. For example, in the case of Huoshenshan hospital, the contractors were able to assemble the construction team of more than 1,500 managers and 12,000 workers in few days [19].

\subsection{External conditions}

\subsubsection{Transportation conditions}

Transporting is regarded as one of the most important processes of prefabricated construction projects[18]. Local transportation regulations, the site transport vehicle capacity, and local transport infrastructure could significantly affect the time that prefabricated modules being transported to the site and the occurrence of design risks in prefabricated construction projects[18]. For example, in the comparison to traditional on-site construction, transportation restriction is a notable disadvantage in prefabricated construction projects, which lead to the delay and inefficiency [8]. Besides, every country's customs are different from each other. When transporting the elements of prefabricated construction projects internationally, the custom delay may show up at border crossing. 


\subsubsection{Regulations}

Regulation aspects are very significant in the design process of the prefabricated construction projects [18]. Every project should obey the requirements of the regulation [18]. Regulation aspects should include content such as building codes, standards, and planning permission. Ineffective regulation and erratic policies are regarded as the reasons for the delay in prefabricated construction projects. For instance, in the UK, the Construction Design Management Regulations 2015 request project stakeholders to estimate the risk of health and safety better so that they can eliminate the reworks because of the health and safety issues, which could speed up the process of prefabricated construction projects[20].

\subsubsection{Weather}

During the whole process of the prefabricated construction project, the weather is an important factor that can influence the schedule. Severe weather has been regarded as one of the most common factors for affecting on-site construction activities in prefabricated construction projects by several previous studies[13,21]. Thus, the schedules of modular assembling projects are easily subject to inclement weather conditions[13,21] To protect the progress of the prefabricated construction project, it is usual to use historical data to predict the direction of the future weather, such as the wind speed and a year's rainfall capacity [18].

\section{Conclusion}

This review aims to systematically identify and classify determinants that influence the schedule of prefabricated constructions. Based on thematic content analysis of the relevant literature, 13 factors that influence the schedule performance of prefabricated construction projects are identified, which are further classified into 7 categories according to different areas of impact. These 7 categories consist of design, construction techniques, collaboration, coordination, and communication between participants, supply chain, owner, human resource, external conditions. The findings of this study provide valuable clues for both researchers and project practitioners to efficiently implement prefabricated construction projects, especially in urgent situations such as public health issues.

Future research directions for improving time performance in prefabricated construction projects are also proposed as below. First, during the outbreak of COVID 19, the rapid construction of emergency hospitals such as Huoshenshan hospital demonstrates that the significance of industrialized building technologies in dealing with public health issues. Therefore, in future research, it is recommended to study and promote the standardization of prefabricated hospitals to speed up the construction processes. Second, future studies are strongly suggested to consider and explore the application of robots and other advanced technologies in the processes of manufacturing and installation of the modular integrated construction projects. These new technologies are expected to significantly improve the productivity of the construction. Third, future research can investigate appropriate procurement strategy to motivate project participants to improve their efficiency and facilitate the integration among different stakeholders as well as the value chain.

\section{References}

1. Zhong, R.Y.; Peng, Y.; Xue, F.; Fang, J.; Zou, W.; Luo, H.; Thomas Ng, S.; Lu, W.; Shen, G.Q.P.; Huang, G.Q. Prefabricated construction enabled by the Internet-of-Things. Autom. Constr. 2017, 76, 59-70.

2. Smit, R.E. Off-Site Construction Implementation Resource: Off-Site and Modular Construction Explained. In Off-Site Construction Council; National Institute of Building Sciences: Washington, DC, USA, 2014.

3. The People's Daily, Http://www.xinhuanet.com/politics/202004/21/c_1125882638.htm

4. Ibrahim Yahaya Wuni\& Geoffrey Qiping Shen (2019): Critical success factors for modular integrated construction projects: a review, Building Research \& Information,

5. Gibb, A. G. F., \&Isack, F. (2003). Re-engineering through pre- assembly: Client expectations and drivers. Building Research and Information, 31(2), 146-160.

6. Akagi, K., Murayama, K., Yoshida, M., \&Kawahata, J. (2002). Modularization technology in power plant construction. In Proceedings of ICONE10 10th international conference on Nuclear engineering (pp. 21-27), Arlington, VA.

7. Choi, J. O., \& O'Connor, J. T. (2014). Modularization critical success factors accomplishment: Learning from case studies. Construction Research Congress, 1636-1645.

8. Ji, Y., Qi, L., Liu, Y., Liu, X., Li, H. X., \& Li, Y. (20 18). Assessing and prioritising delay factors of prefa bricated concrete building projects in China. Applied Sciences, 8(11),2324.

9. Hsu, P. Y., Angeloudis, P., \&Aurisicchio, M. (2018). Optimal logistics planning for modular construction using two-stage stochastic programming. Automation in Construction, 94, 47-61.

10. Ahmadian, F.F.A.; Akbarnezhad, A.; Rashidi, T.H.; Waller, S.T. Accounting for Transport Times in Planning Off-Site Shipment of Construction Materials. J. Constr. Manag. Econ. 2016, 142, 04015050.

11. Haas, C. T., \&Fagerlund, W. R. (2002). Preliminary research on prefabrication, pre-assembly, modularization and off- site fabrication in construction. Austin, TX. Retrieved from https://smartech.gatech.edu/handle/1853/10883 
12. Rentschler, C., Mulrooney, M., \& Shahani, G. (2016). Modularization: The key to success in today's market. Hydrocarbon Processing, 95(12), 27-30.

13. Li, C. Z., Zhong, R. Y., Xue, F., Xu, G., Chen, K., Huang, G. G., \& Shen, G. Q. (2017). Integrating RFID and BIM technol- ogies for mitigating risks and improving schedule perform- ance of prefabricated house construction. Journal ofCleaner Production, 165, 1048-1062.

14. Hwang, B.-G., Shan, M., \&Looi, K.-Y. (2018a). Key constraints and mitigation strategies for prefabricated prefinished volu- metric construction. Journal of Cleaner Production, 183, 183-193.

15. Pan, W., \& Hon, C. K. (2018). Modular integrated construc- tion for high-rise buildings. Proceedings of the Institution of Civil Engineers - Municipal Engineer, 1-12.

16. Tam, V. W. Y., Tam, C. M., \& Ng, W. C. Y. (2007). On prefab- rication implementation for different project types and pro- curement methods in Hong Kong. Journal of Engineering, Design and Technology, 5(1), 68-80.

17. Pan, W., Gibb, A. G. F., \& Dainty, A. R. J. (2007). Perspective of UK housebuilders on the use of offsite modern methods of construction. Construction Management and Economics, 25(2), 183-194.

18. MontySutrisna, Jack Goulding, (2019) "Managing information flow and design processes to reduce design risks in offsite construction projects", Engineering, Construction and Architectural Management, https://doi.org/10.1108/ECAM-112017-0250

19. People's daily :About 40000 builders built huoshenshan and leishenshan hospital in 10 days2020-04-

$21 \mathrm{http}: / /$ www.xinhuanet.com/politics/202004/21/c_1125882638.htm

20. Huoshenshan hospital -- this is "Chinese speed" .Li Pengxiang, LiJinfeng, Liang Jianqiang HSE (2015), "Managing health and safety in construction: construction (Design and Management) Regulations 2015: guidance on regulations", Health and Safety Executive, London

21. Gündüz, M., Nielsen, Y., \& Özdemir, M. (2013). Qu antification of delay factors using the relative import ance index method for construction projects in Turke y. J. Manag. Eng., 29(2), 133-139.

22. X. Li, M. AlHussein, Z. Lei, Z. Ajweh, Risk identific ation and assessment of modular construction utilizin g fuzzy analytic hierarchy process (AHP) and simu- 1 ation, Can. J. Civ. Eng. 40 (12) (2013) 1184-1195 